\title{
Photooxidation Contribution Study on the Decomposition of Azo Dyes in Aqueous Solutions by VUV-Based AOPs
}

\author{
Chih-Ming Ma, ${ }^{1}$ Gui-Bing Hong, ${ }^{1}$ Hua-Wei Chen, ${ }^{1}$ Nguyen-Thi Hang, ${ }^{2}$ \\ and Yung-Shuen Shen ${ }^{3}$ \\ ${ }^{1}$ Department of Cosmetic Application and Management, St. Mary's Medicine Nursing and Management College, No. 100, Lane 265, \\ San-Shing Road, Sec. 2, San-Shing Shiang, Yi-Lan 266, Taiwan \\ ${ }^{2}$ Department of Environmental Engineering, Da-Yeh University, No. 168, University Road, Dacun, Changhua 512, Taiwan \\ ${ }^{3}$ Holistic Education Center, Mackay Medical College, No. 46, Sec. 3, Jhong-Jheng Road, San-Jhih, Taipei City 252, Taiwan \\ Correspondence should be addressed to Yung-Shuen Shen, ysshen@mmc.edu.tw
}

Received 14 February 2011; Revised 25 September 2011; Accepted 25 September 2011

Academic Editor: F. Yakuphanoglu

Copyright (c) 2011 Chih-Ming Ma et al. This is an open access article distributed under the Creative Commons Attribution License, which permits unrestricted use, distribution, and reproduction in any medium, provided the original work is properly cited.

The effects of $\mathrm{pH}$ value, VUV intensity, initial dye concentration, initial $\mathrm{H}_{2} \mathrm{O}_{2}$ concentration, and $\mathrm{TiO}_{2}$ loading dose on the degradation of three azo dyes: acid Orange 8, acid Blue 29, and acid Blue 113 were studied to explore and compare the treatment efficiencies among the adopted AOPs. It was found that $\mathrm{pH}$ played an important role in the degradation of dyes using VUV irradiation. For $\mathrm{VUV} / \mathrm{H}_{2} \mathrm{O}_{2}, \mathrm{VUV} / \mathrm{TiO}_{2}$, and $\mathrm{VUV} / \mathrm{TiO}_{2} / \mathrm{H}_{2} \mathrm{O}_{2}$ processes, the decoloration rates of the three azo dyes were more efficient under acidic conditions relative to alkaline conditions. The degradation rates of dyes increased with increasing concentrations of $\mathrm{H}_{2} \mathrm{O}_{2}$, but reaction rates were retarded at high concentrations of $\mathrm{H}_{2} \mathrm{O}_{2}$ because the $\mathrm{H}_{2} \mathrm{O}_{2}$ compound acted as a scavenger of the hydroxyl radical. In this paper, three azo dyes were decomposed efficiently by VUV irradiation only demonstrating the effectiveness of VUV direct photolysis.

\section{Introduction}

Environmental protection has been a globally important issue for the past few decades. Environmental data show that industrial wastewater mainly consists of heavy metals, volatile organic compounds (VOCs), cyanide, COD, oil, suspended solids, and sulfides. Dyes are one of the major sources of pollutants and extensively used in the textile industry, photocatalytic industry, and in photochemical applications [1]. Treatment of colored wastewaters produced by textile and other industries is a serious problem that has attracted the attention of many researchers during last few decades. In general, treatment methods of wastewater containing dyes can be divided into two main groups: (1) chemical or physical dye removal methods, which refer to the process called decoloration and (2) dye removal by means of biodegradation. Physical methods of decoloration include different precipitation methods (coagulation, flocculation, and sedimentation), adsorption (on activated carbon, biological sludge, and silica gel), filtration, reverse, and osmosis. Chemical processes involved in chemical dye removal methods include reduction, oxidation, complexometric methods, ion exchange, and neutralization. Biological treatment can be conducted aerobically or anaerobically.

Practically speaking, each dye removal method has disadvantages. Physical methods are usually nondestructive, requiring expensive posttreatment processing. Chemical treatment methods using strong oxidants such as chlorine or ozone successfully treat dye wastes, but are also expensive due to high costs associated with the chemicals. Biological treatment methods do not effectively treat synthetic dyes because synthetic dyes are highly resistant to aerobic degradation. A chemical method has been applied and has produced interesting results in the treatment of wastewater containing dye stuffs called advanced oxidation processes (AOPs). In recent years, the use of AOPs technology to remove organic pollutants from air or wastewater has received great attention [2-8]. These methods are an application of UV radiation 
<smiles>Cc1cc(S(=O)(=O)O[Na])ccc1N=Nc1c(O)ccc2ccccc12</smiles>

(a)

(b)<smiles>COS(=O)(=O)c1cccc(/N=N/c2ccc(N=Nc3ccc(Nc4ccccc4)c4c(S(=O)(=O)O[Na])cccc34)c3ccccc23)c1</smiles>

(c)

Figure 1: Chemical structure of (a) acid Orange 8; (b) acid Blue 29; (c) Blue 113.

in the presence of some oxidants which can generate strong oxidable radicals to decompose pollutants in the solution.

During the last decade, chemical organic wastewater decomposition techniques have been developed. Among these techniques, UV irradiation in combination with powerful oxidants (e.g., $\mathrm{O}_{3}$ and $\mathrm{H}_{2} \mathrm{O}_{2}$ ) may be a promising method for effectively removing color and refractory organics from effluent. This method does not generate chemical sludge, and the toxicity of wastewater is generally reduced. A considerable disadvantage to the degradation processes introduced above is the need to add external agents into the aqueous medium. In such situations, the effectiveness of the processes relies on solid-liquid and gas-liquid mass transfer that sometimes limits the degradation processes. The development of novel vacuum light (VUV) sources over the last few years has opened up new possibilities for in-situ generation of hydroxyl radicals $\left(\mathrm{OH}^{*}\right)$ [9-11]. Hence, the vacuum-UV photolysis of water $\left(\mathrm{H}_{2} \mathrm{O}-\mathrm{VUV}\right)$ is still a field of active research compared to other AOPs [12]. As exhibited in (1), the special requirements of the VUV photolysis of water are related to the formation of a high local concentration of hydroxyl radicals $\left(\mathrm{OH}^{*}\right)$ and a series of other species within a photochemical reaction zone of less than $0.1 \mathrm{~mm}[13,14]$. The high energy UV light causes the homolysis of water into hydroxyl radicals and hydrogen molecules. Light sources that can support this process include "ozone-producing" low-pressure mercury lamps (emitting at $185 \mathrm{~nm}$ ) and the
Xe excimer lamp (emitting at $172 \mathrm{~nm}$ ). The depth of this reaction volume is defined by the high absorption crosssection of water at the wavelength

$$
\mathrm{H}_{2} \mathrm{O} \underset{\operatorname{vUV}(\lambda<190 \mathrm{~nm})}{\longrightarrow} \mathrm{H}^{*}+\mathrm{OH}^{\circ}
$$

Oxygen molecules in an aqueous solutions can be excited by VUV using a wavelength ranging between $140 \mathrm{~nm}$ to $190 \mathrm{~nm}$ to generate hydroxyl radicals as shown bellow [15]:

$$
\begin{gathered}
3 \mathrm{O}_{2}+185 \mathrm{~nm} h \boldsymbol{h} \longrightarrow 2 \mathrm{O}_{3} \\
\mathrm{O}_{3}+\mathrm{H}_{2} \mathrm{O}+h v \longrightarrow \mathrm{O}_{2}+\mathrm{H}_{2} \mathrm{O}_{2} \\
\mathrm{H}_{2} \mathrm{O}_{2}+h v \longrightarrow 2 \mathrm{OH}^{.}
\end{gathered}
$$

The VUV irradiation of contaminated water provides a simple technique for allowing the oxidation and mineralization of water contaminants without the addition of supplementary oxidants. For example, in the semiconductor industry, VUV irradiation has been used to treat ultrapure water. However, research is still necessary to fully understand principles associated with the VUV-induced water treatment photochemical process.

Moreover, many researchers agree that titanium dioxide, at present, is one of the better photocatalysts for environmental applications. Relative to other photocatalysts, titanium dioxide has advantages such as a high activity high 


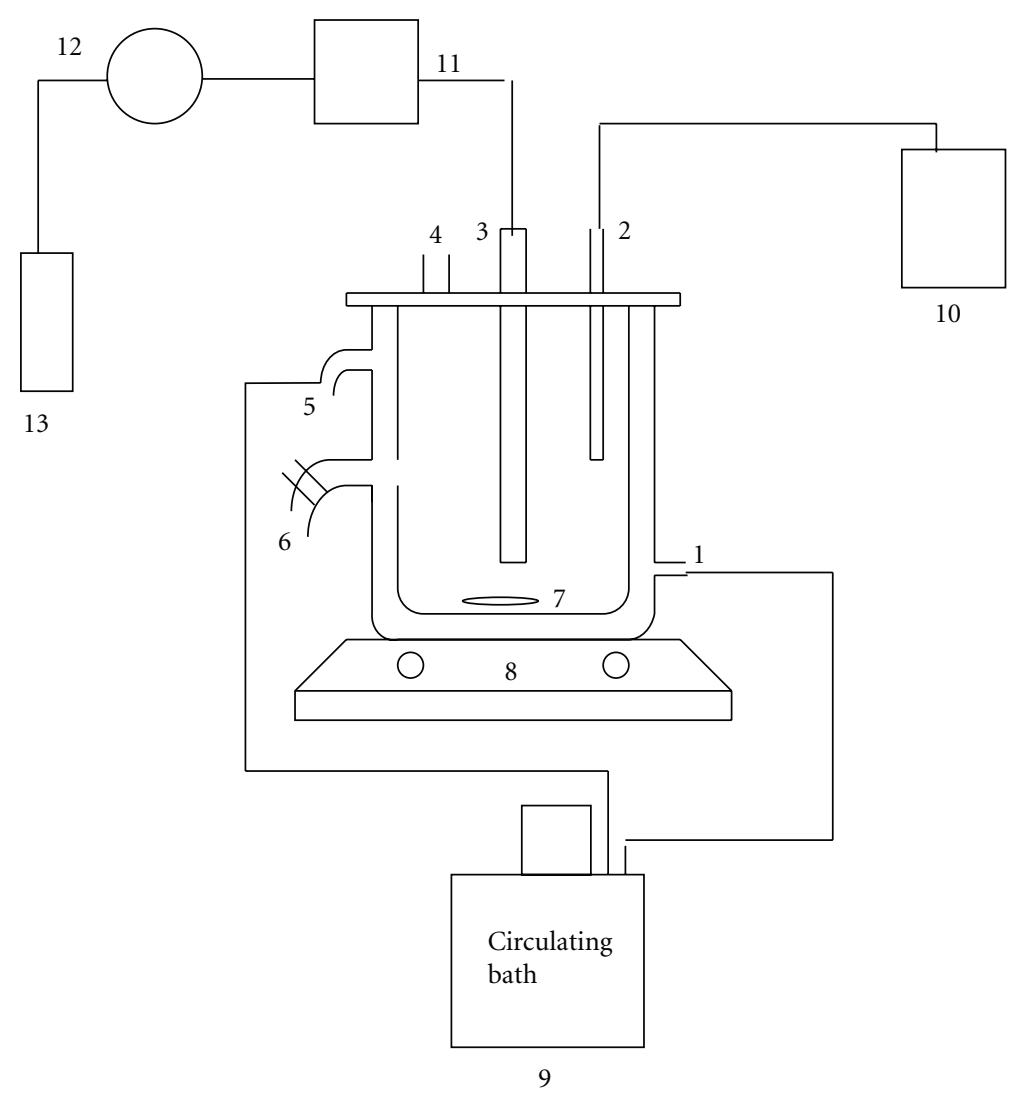
(1) Input of water to control temperature
(8) Magnetic stirrer
(2) $\mathrm{pH}$ controller
(9) Circulating bath
(3) VUV lamp
(10) $\mathrm{pH}$ meter
(4) Input of $\mathrm{pH}$ adjusting solution
(11) Pen ray power supply
(5) Output of water to control temperature
(12) Variable voltage transformer
(6) Sampling port
(13) Electricity
(7) Stir bar

Figure 2: The schematic diagram of the reactor system.

stability to light illumination, low cost and nontoxiciy [16]. For these reasons, there are much application and development of $\mathrm{TiO}_{2}$ photocatalytic technique $[17,18]$. In this study, $\mathrm{TiO}_{2}$ is used to treat azo dye compounds in aqueous solutions in this paper. The aim of this paper is to investigate reaction behaviors associated with the decomposition of dyecontaining wastewaters by VUV-based advanced oxidation processes (AOPs). The effects of $\mathrm{pH}$ value, VUV intensity, initial dye concentration, initial $\mathrm{H}_{2} \mathrm{O}_{2}$ concentration, and $\mathrm{TiO}_{2}$ loading dose on the degradation of three azo dyes: acid Orange 8 , acid Blue 29, and acid Blue 113 were studied to explore and compare the treatment efficiencies among the adopted AOPs.

\section{Methods and Materials}

To differentiate the effects of the VUV intensity, initial dye concentration, initial $\mathrm{H}_{2} \mathrm{O}_{2}$ concentration, and $\mathrm{TiO}_{2}$ loading dose on the degradation of three azo dyes, experiments were conducted and studied in the following systems: (1) $185 \mathrm{~nm}$ VUV direct photolysis system, (2) $185 \mathrm{~nm} \mathrm{VUV/} \mathrm{H}_{2} \mathrm{O}_{2}$ system, (3) $185 \mathrm{~nm} \mathrm{VUV/TiO}{ }_{2}$ system. Each system employed in this research contained one batch annular photoreactor. The outer tube of the annular photoreactor was made entirely of Pyrex glass with an effective volume of $2.0 \mathrm{~L}$ and was water-jacketed to maintain constant solution temperature at $25^{\circ} \mathrm{C}$. The low-pressure mercury $185 \mathrm{~nm}$ vacuum-UV lamp was inserted directly into the reactor at the center. The light intensity of the UV lamp was kept constant with approximately 12 watts maximum output. The solution $\mathrm{pH}$ value was kept manually constant at desired levels using $\mathrm{NaOH}$ and $\mathrm{H}_{2} \mathrm{SO}_{4}$ solutions. The dyes and $\mathrm{H}_{2} \mathrm{O}_{2}$ and other chemicals used were reagent grade, and all experimental solutions were prepared with deionized water. In this study, three azo dye compounds were used and molecular structure is shown in Figure 1. 


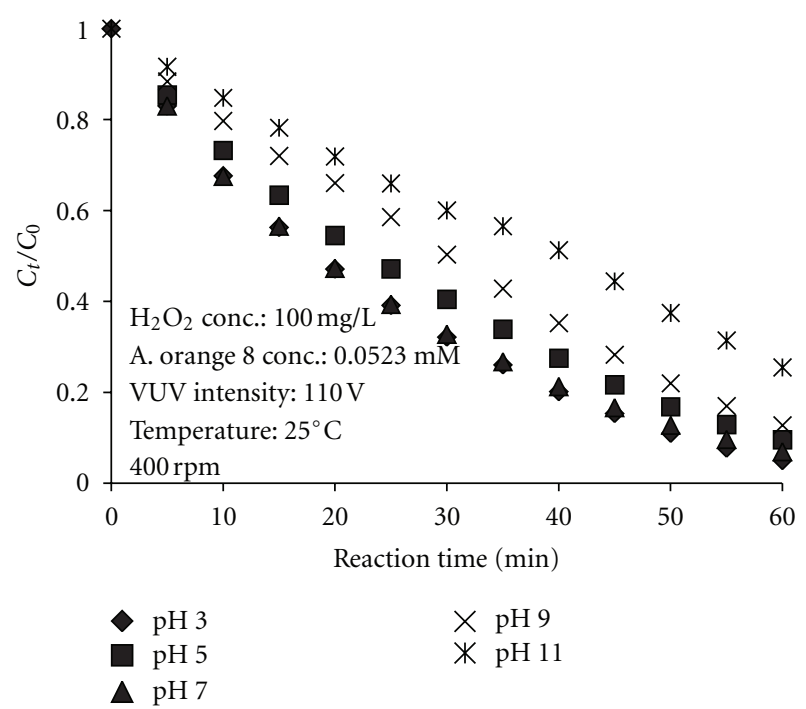

FIgure 3: The degradation of acid Orange 8 at different $\mathrm{pH}$ in aqueous solutions by $\mathrm{VUV} / \mathrm{H}_{2} \mathrm{O}_{2}$ process.

The solution of dyes was added to the reactor with a predetermined amount of $\mathrm{H}_{2} \mathrm{O}_{2}$ solution. Typical reaction runs lasted $60 \mathrm{~min}$. At desired time intervals, aliquots of solution were withdrawn from the sampling port, which was located at the bottom of the reactor, and analyzed for dyes and $\mathrm{H}_{2} \mathrm{O}_{2}$ concentrations. Total sample volumes were kept below $2 \%$ of the total reactor volume. Each run of the experiments in this work was replicated twice. The standard deviation of the concentration of dyes was analyzed to be $\pm 0.1 \mathrm{mg} / \mathrm{L}$, respectively. The concentration of $\mathrm{H}_{2} \mathrm{O}_{2}$ in the aqueous solution was determined by the KI titration method. The UV light absorbances of reacting solutions were detected by a HITACH U-2000 UV/Visible spectrophotometer.

All experiments considering $\mathrm{pH}$ as an effect lasted in 60 minutes for photodestruction of three azo dyes in various $\mathrm{pH}$. The solutions of dye were adjusted to the desired $\mathrm{pH}$ by adding $\mathrm{H}_{2} \mathrm{SO}_{4}$ or $\mathrm{NaOH}$. Additions of $\mathrm{H}_{2} \mathrm{SO}_{4}$ and $\mathrm{NaOH}$ were minimized to avoid changing the volume of the reaction mixture. All runs were carried under the same conditions: $0.0523 \mathrm{mM}$ of initial dye concentration, $100 \mathrm{mg} / \mathrm{L}$ of $\mathrm{H}_{2} \mathrm{O}_{2}$ concentration, $25^{\circ} \mathrm{C}$ of reaction temperature, and $400 \mathrm{rpm}$ of stirring speed. Reactions were assessed at five $\mathrm{pH}$ levels: 3,5 , 7, 9, and 11. In $\mathrm{VUV} / \mathrm{TiO}_{2}$ or $\mathrm{VUV} / \mathrm{TiO}_{2} / \mathrm{H}_{2} \mathrm{O}_{2}$ experiments, the dye solution was placed in the reactor and mixed with desired concentration of $\mathrm{TiO}_{2}$ powder such as $0.5 \mathrm{~g} / \mathrm{L}$ by the magnetic stirrer in $10 \mathrm{~min}$. The schematic diagram of the reactor system employed in this research is shown in Figure 2.

\section{Results and Discussion}

3.1. pH Effect on the Degradation of Three Azo Dyes in Aqueous Solution by VUV/ $\mathrm{H}_{2} \mathrm{O}_{2}$ Process. The decomposition of acid Orange 8 by VUV/ $\mathrm{H}_{2} \mathrm{O}_{2}$ process at different $\mathrm{pH}$ values is shown in Figure 3. Results indicated that the photolytic dye degradation appeared to be best at acidic conditions for acid
Orange 8. This results match findings of Shen and Lin [19]. Photolytic dye degradation of acid Blue 29 and acid Blue 113 was best at a neutral $\mathrm{pH}$, which matches findings of AlHamedi et al. [20]. According to the results of Alhamedi et al. [20] and Daneshvar et al. [21], hydrogen peroxide will be deprotonated with the formation of $\mathrm{H}_{2} \mathrm{O}_{2} / \mathrm{HO}_{2}{ }^{-}$ equilibrium under alkaline conditions. The $\mathrm{HO}_{2}{ }^{-}$species reacts with nondissociated molecules of $\mathrm{H}_{2} \mathrm{O}_{2}$ according to (6), which leads to oxygen and water, instead of producing hydroxyl radicals under VUV irradiation. Therefore, the instantaneous concentration of $\mathrm{OH}^{*}$ is lower than expected: see (5), (6), and (7)

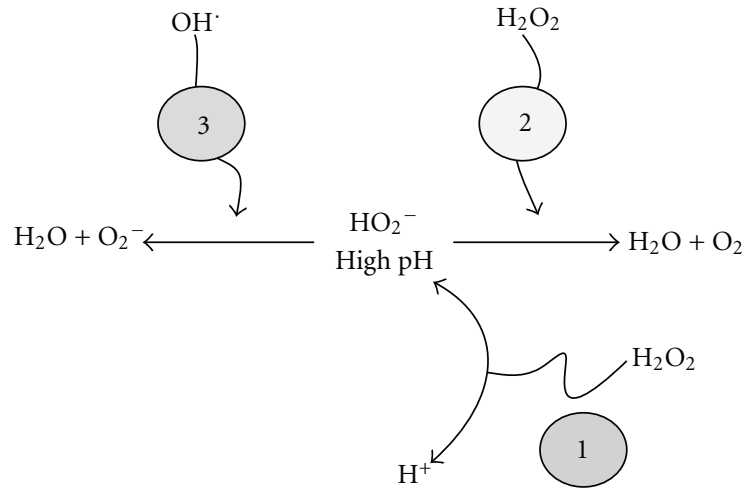

$$
\begin{gathered}
\text { (1) } \mathrm{H}_{2} \mathrm{O}_{2} \stackrel{\mathrm{pK}_{\mathrm{a}}=11.6}{\longrightarrow} \mathrm{HO}_{2}^{-}+\mathrm{H}^{+} \\
\text {(2) } \mathrm{HO}_{2}{ }^{-}+\mathrm{H}_{2} \mathrm{O}_{2} \longrightarrow \mathrm{H}_{2} \mathrm{O}+\mathrm{O}_{2}+\mathrm{OH}^{-} \\
\text {(3) } \mathrm{OH}+\mathrm{HO}_{2}^{-} \longrightarrow \mathrm{H}_{2} \mathrm{O}+\mathrm{O}_{2}^{-}
\end{gathered}
$$

The observed first-order reaction $k$ values at different $\mathrm{pH}$ in the degradation of three azo dyes by $\mathrm{VUV} / \mathrm{H}_{2} \mathrm{O}_{2}$ process are given in Table 1.

Based on the above findings, it was recognized that at the same dye concentration of $0.0523 \mathrm{mM}$, acid Orange 8 was decomposed more rapidly relative to acid Blue 29 and acid Blue 113. Decomposition reached approximately $90 \%$ after 60 min of irradiation time, whereas only approximately $50 \%$ of acid Blue 29 and $60 \%$ of acid Blue 113 were decomposed in the same irradiation time. In terms of reaction rate, the results are ordered as follows: acid Orange $8>$ acid Blue $29>$ acid Blue 113 at $\mathrm{pH} 3$, acid Orange $8>$ acid Blue $113>$ acid Blue 29 at $\mathrm{pH} 7$ and $\mathrm{pH} 11$.

Azo dye compounds can be decomposed simultaneously by VUV direct photolysis and hydroxyl radical indirect oxidation in aqueous solutions by $\mathrm{VUV} / \mathrm{H}_{2} \mathrm{O}_{2}$ process to generate some organic intermediates. The final products of carbon dioxide and water were formed. Decomposition of pollutants in aqueous solutions by the $\mathrm{VUV} / \mathrm{H}_{2} \mathrm{O}_{2}$ process was primarily attributed to the competing reaction, direct photolysis, and the hydroxyl radical attack. The position pathway of the three azo dyes by the $\mathrm{VUV} / \mathrm{H}_{2} \mathrm{O}_{2}$ process is similar to results of Shen and Lin [19]. Assuming that both direct photolysis and indirect oxidation of the three azo dyes were pseudo-first order, the removal rate constant for free radical destruction $\left(k_{\mathrm{OH}}\right)$ can be determined by 
TABLE 1: $k$ values at different $\mathrm{pH}$ in the degradation of three azo dyes by $\mathrm{VUV} / \mathrm{H}_{2} \mathrm{O}_{2}$ process.

\begin{tabular}{|c|c|c|c|c|c|c|}
\hline \multirow{2}{*}{$\mathrm{pH}$} & \multicolumn{2}{|c|}{ Acid Orange 8} & \multicolumn{2}{|c|}{ Acid Blue 29} & \multicolumn{2}{|c|}{ Acid Blue 113} \\
\hline & $k\left(\min ^{-1}\right)$ & $R^{2}$ & $k\left(\min ^{-1}\right)$ & $R^{2}$ & $k\left(\min ^{-1}\right)$ & $R^{2}$ \\
\hline 3 & 0.0474 & 0.9779 & 0.0102 & 0.9993 & 0.0081 & 0.9977 \\
\hline 5 & 0.0377 & 0.9822 & 0.0090 & 0.9962 & 0.0133 & 0.9978 \\
\hline 7 & 0.0430 & 0.9907 & 0.0124 & 0.9985 & 0.0175 & 0.9994 \\
\hline 9 & 0.0331 & 0.9619 & 0.0144 & 0.9986 & 0.0104 & 0.9928 \\
\hline 11 & 0.0213 & 0.9659 & 0.0097 & 0.9751 & 0.0168 & 0.9883 \\
\hline
\end{tabular}

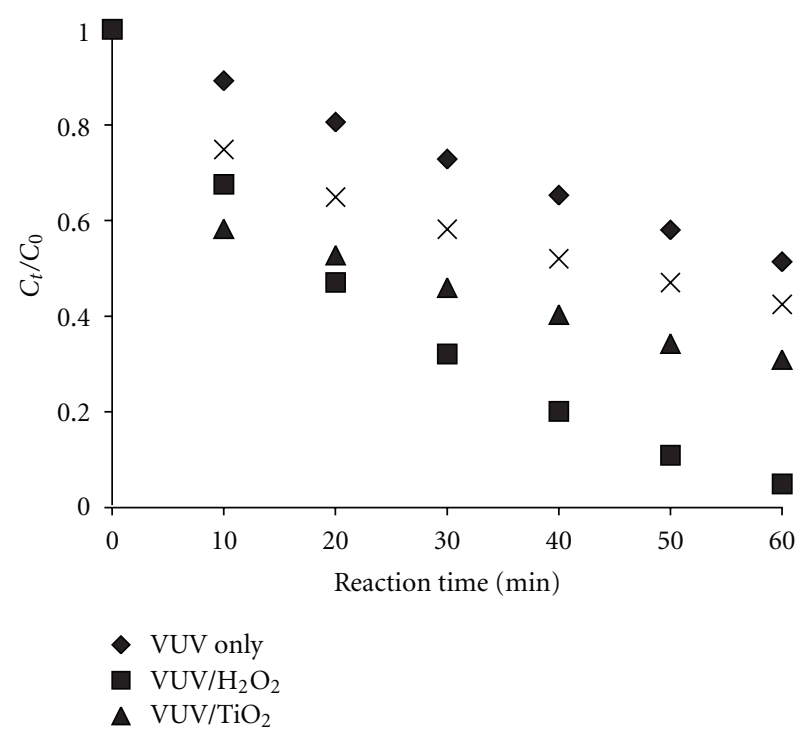

FIGURE 4: The degradation of acid Orange 8 under VUV irradiation at acidic condition, $[$ Dye $]=0.0523 \mathrm{mM},\left[\mathrm{H}_{2} \mathrm{O}_{2}\right]=100 \mathrm{mg} / \mathrm{L},\left[\mathrm{TiO}_{2}\right]$ $=0.5 \mathrm{~g} / \mathrm{L}, \mathrm{VUV}$ intensity $=110 \mathrm{~V}, \mathrm{pH} 3,25^{\circ} \mathrm{C}, 400 \mathrm{rpm}$.

difference between the rate constant of $\mathrm{VUV} / \mathrm{H}_{2} \mathrm{O}_{2}$ treatment $\left(k_{\mathrm{VUV} / \mathrm{H}_{2} \mathrm{O}_{2}}\right)$ and the rate constant of VUV system alone $\left(k_{\text {VUVonly }}\right)((8)$ and $(9))$.

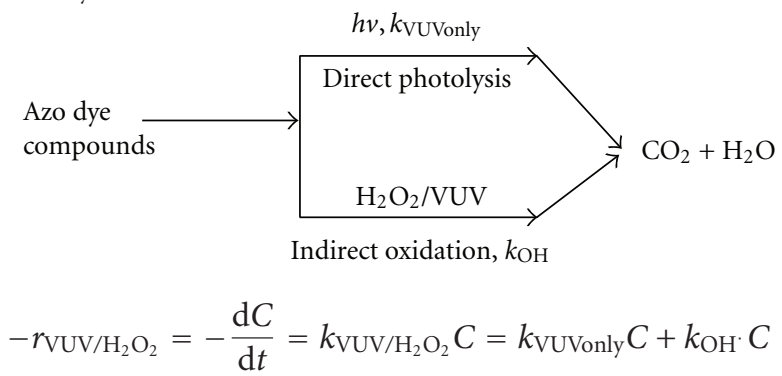

$$
k_{\mathrm{OH}}=k_{\mathrm{VUV} / \mathrm{H}_{2} \mathrm{O}_{2}}-k_{\mathrm{VUVonly}}
$$

The pseudo-first-order decomposition rate constants of Acid Orange 8 by direct photolysis and the $\mathrm{VUV} / \mathrm{H}_{2} \mathrm{O}_{2}$ process are summarized in Table 2. The contribution to the decomposition of Acid Orange 8 by hydroxyl radical destruction was clearly decreased with increasing solution $\mathrm{pH}$ values. At acidic and neutral conditions, the contribution to the decomposition of the three azo dyes was higher than at the alkaline indirect oxidation process. Acidic and alkaline conditions failed to create significant differences in the indirect oxidation of acid Blue 113. The photon absorptions of acid Blue 113 ( $\varepsilon_{\text {Blue113 }}$ ) at acidic, neutral, and alkaline condition are close together: 0.0563, 0.0593, and 0.040 , respectively. On the other hand, direct photolysis was the most important contribution for the removal of azo dyes in high-alkaline solutions.

3.2. Comparison of the Degradation of Azo Dyes in Aqueous Solution by Various AOPs. The degradation of Acid Orange 8 by the four processes is shown in Figure 4. In terms of decomposition rate efficiency, the Acid orange 8 degredation processes are ordered as follows: $\mathrm{VUV} / \mathrm{H}_{2} \mathrm{O}_{2}>\mathrm{VUV} / \mathrm{TiO}_{2}>$ $\mathrm{VUV} / \mathrm{TiO}_{2} / \mathrm{H}_{2} \mathrm{O}_{2}>\mathrm{VUV}$ only process. No significant decomposition was observed when adding $\mathrm{H}_{2} \mathrm{O}_{2}$ into VUV/TiO 2 process or adding $\mathrm{TiO}_{2}$ into $\mathrm{VUV} / \mathrm{H}_{2} \mathrm{O}_{2}$ process under acidic conditions. The highest treatment efficiency of Acid Orange 8 was approximately 95\% after 60 min using a VUV/ $\mathrm{H}_{2} \mathrm{O}_{2}$ process. Treatment efficiency associated with the $\mathrm{VUV} / \mathrm{TiO}_{2} / \mathrm{H}_{2} \mathrm{O}_{2}$ process was the lowest. This result may possibly be due to a slowing in the generation of hydroxyl radicals due to effects associated with excess amounts of $\mathrm{TiO}_{2}$ and $\mathrm{H}_{2} \mathrm{O}_{2}$. The pseudo-first-order rate constants $\left(k_{\mathrm{app}}\right.$, $\mathrm{min}^{-1}$ ) of the decomposition of dyes at various $\mathrm{pH}$ values by $\mathrm{VUV} / \mathrm{TiO}_{2}$ and $\mathrm{VUV} / \mathrm{TiO}_{2} / \mathrm{H}_{2} \mathrm{O}_{2}$ process are determined and summarized in Table 3. Table 4 displays the summarized results for comparison among treatment efficiencies of dyes by various AOPs and illustrates differences of decomposition rates associated with the three dyes and AOPs. To evaluate oxidation efficiencies of the $\mathrm{H}_{2} \mathrm{O}_{2}$ and $\mathrm{TiO}_{2}$ oxidants used in this study, the ratio between reaction rate constants $(k)$ at different $\mathrm{pH}$ levels with doses of $\mathrm{H}_{2} \mathrm{O}_{2}$ and $\mathrm{TiO}_{2}$ was calculated, as presented in Table 5. The ratio $k /\left[\mathrm{H}_{2} \mathrm{O}_{2}\right]$ was always larger than the ratio $k /\left[\mathrm{TiO}_{2}\right]$. It was found that the oxidation efficiency associated with $\mathrm{H}_{2} \mathrm{O}_{2}$ processes was larger than those with $\mathrm{TiO}_{2}$ processes and that the AOP decomposition rate of dyes in $\mathrm{H}_{2} \mathrm{O}_{2}$ processes was faster than those using $\mathrm{TiO}_{2}$ (i.e., $k /\left[\mathrm{H}_{2} \mathrm{O}_{2}\right]>k /\left[\mathrm{TiO}_{2}\right]$ ). According to Liu et al. [22], these azo dyes contain the sodium ion which is easily dissociated in water and leaves the dye molecule with negative charges, so it makes the system easier to be adsorbed on the surface of the catalyst to proceed reaction at lower $\mathrm{pH}$ value. Keiichi et al. [23] also found that these dyes are negatively charged due to sulfonate group and hydroxyl group; thus positively charged $\mathrm{TiO}_{2}$ surface adsorbed more azo dyes at lower $\mathrm{pH}$ value, and more decomposition was 
TABLE 2: The summary of the pseudo-first-order decomposition rate constant, $k\left(\mathrm{~min}^{-1}\right)$, of Acid Orange 8 by direct photolysis and the $\mathrm{VUV} / \mathrm{H}_{2} \mathrm{O}_{2}$ process.

\begin{tabular}{lcccccc}
\hline & & \multicolumn{2}{c}{ Direct photolysis } & \multicolumn{2}{c}{ Indirect oxidation } \\
$\mathrm{pH}$ & $k_{\mathrm{VUV} / \mathrm{H}_{2} \mathrm{O}_{2}}$ & $k_{\mathrm{VUV} \text { nly }}$ & Contribution $(\%)$ & $k_{\mathrm{OH}}$ & Contribution & $k_{\mathrm{VUV} / \mathrm{H}_{2} \mathrm{O}_{2}} / k_{\mathrm{VuVonly}}(\%)$ \\
\hline 3 & 0.0474 & 0.0108 & 22.78 & 0.0366 & 77.22 & 4.39 \\
5 & 0.0377 & 0.0106 & 28.12 & 0.0271 & 71.88 & 3.56 \\
7 & 0.0430 & 0.0135 & 31.40 & 0.0295 & 68.60 & 3.19 \\
9 & 0.0331 & 0.0119 & 35.95 & 0.0212 & 64.05 & 2.78 \\
11 & 0.0213 & 0.0146 & 68.55 & 0.0067 & 31.45 & 1.46 \\
\hline
\end{tabular}

TABLE 3: The $k_{\text {app }}\left(\mathrm{min}^{-1}\right)$ values at different $\mathrm{pH}$ in both $\mathrm{VUV} / \mathrm{TiO}_{2}$ and $\mathrm{VUV} / \mathrm{TiO}_{2} / \mathrm{H}_{2} \mathrm{O}_{2}$ process.

\begin{tabular}{|c|c|c|c|c|c|c|}
\hline \multirow[b]{3}{*}{$\mathrm{pH}$} & \multicolumn{6}{|c|}{$k_{\text {app }}$} \\
\hline & \multicolumn{2}{|c|}{ Acid Orange 8} & \multicolumn{2}{|c|}{ Acid Blue 29} & \multicolumn{2}{|c|}{ Acid Blue 113} \\
\hline & $\mathrm{VUV} / \mathrm{TiO}_{2}$ & $\mathrm{VUV} / \mathrm{TiO}_{2} / \mathrm{H}_{2} \mathrm{O}_{2}$ & $\mathrm{VUV} / \mathrm{TiO}_{2}$ & $\mathrm{VUV} / \mathrm{TiO}_{2} / \mathrm{H}_{2} \mathrm{O}_{2}$ & $\mathrm{VUV} / \mathrm{TiO}_{2}$ & $\mathrm{VUV} / \mathrm{TiO}_{2} / \mathrm{H}_{2} \mathrm{O}_{2}$ \\
\hline 3 & 0.0148 & 0.0120 & 0.0086 & 0.0115 & 0.2469 & 0.2729 \\
\hline 5 & 0.0151 & 0.0108 & 0.0065 & 0.0079 & 0.0324 & 0.0248 \\
\hline 7 & 0.0141 & 0.0103 & 0.0044 & 0.0033 & 0.0068 & 0.0064 \\
\hline 9 & 0.0129 & 0.0091 & 0.0044 & 0.0027 & 0.0061 & 0.0065 \\
\hline 11 & 0.0096 & 0.0075 & 0.0044 & 0.0037 & 0.0060 & 0.0062 \\
\hline
\end{tabular}

TABLE 4: Summarized result for comparison among treatment efficiencies of dyes by various AOPs.

\begin{tabular}{lccc}
\hline Items & Acid Orange 8 & Acid Blue 29 & Acid Blue 113 \\
\hline Condition & {$[$ Dye $]=0.0523 \mathrm{mM},\left[\mathrm{H}_{2} \mathrm{O}_{2}\right]=100 \mathrm{mg} / \mathrm{L},\left[\mathrm{TiO}_{2}\right]=0.5 \mathrm{~g} / \mathrm{L}, \mathrm{VUV}$ intensity $=110 \mathrm{~V}, 25^{\circ} \mathrm{C}, 400 \mathrm{rpm}$} \\
\hline \multirow{2}{*}{ pH 3} & $\mathrm{VUV} / \mathrm{H}_{2} \mathrm{O}_{2}>\mathrm{VUV} / \mathrm{TiO}_{2}>$ & $\mathrm{VUV} / \mathrm{TiO}_{2} / \mathrm{H}_{2} \mathrm{O}_{2}>\mathrm{VUV} / \mathrm{TiO}_{2}>$ & $\mathrm{VUV} / \mathrm{TiO}_{2} / \mathrm{H}_{2} \mathrm{O}_{2}>\mathrm{VUV} / \mathrm{TiO}_{2}>$ \\
& $\mathrm{VUV} / \mathrm{TiO}_{2} / \mathrm{H}_{2} \mathrm{O}_{2}>\mathrm{VUV}$ only & $\mathrm{VUV} / \mathrm{H}_{2} \mathrm{O}_{2}>\mathrm{VUV}$ only & $\mathrm{VUV} / \mathrm{H}_{2} \mathrm{O}_{2}>\mathrm{VUV}$ only \\
\hline $\mathrm{pH} 7$ & $\mathrm{VUV} / \mathrm{H}_{2} \mathrm{O}_{2}>\mathrm{VUV} / \mathrm{TiO}_{2}>\mathrm{VUV} / \mathrm{TiO}_{2} / \mathrm{H}_{2} \mathrm{O}_{2}>\mathrm{VUV}$ only \\
\hline $\mathrm{pH} 11$ & $\mathrm{VUV} / \mathrm{H}_{2} \mathrm{O}_{2}>\mathrm{VUV}$ only $>\mathrm{VUV} / \mathrm{TiO}_{2}>\mathrm{VUV} / \mathrm{TiO}_{2} / \mathrm{H}_{2} \mathrm{O}_{2}$ \\
\hline
\end{tabular}

TABLE 5: The comparison of oxidation efficiency.

\begin{tabular}{|c|c|c|c|c|c|}
\hline \multirow[b]{2}{*}{ Dye } & \multirow[b]{2}{*}{$\mathrm{pH}$} & \multicolumn{2}{|c|}{$\mathrm{VUV} / \mathrm{H}_{2} \mathrm{O}_{2}$ process } & \multicolumn{2}{|c|}{$\mathrm{VUV} / \mathrm{TiO}_{2}$ process } \\
\hline & & $k\left(\min ^{-1}\right)$ & $k /\left[\mathrm{H}_{2} \mathrm{O}_{2}\right]\left(\min ^{-1} \mathrm{mM}^{-1}\right)$ & $\begin{array}{c}k_{\mathrm{app}} \\
\left(\min ^{-1}\right)\end{array}$ & $\begin{array}{c}k_{\mathrm{app}} /\left[\mathrm{TiO}_{2}\right] \\
\left(\mathrm{min}^{-1} \mathrm{mM}^{-1}\right)\end{array}$ \\
\hline \multirow{5}{*}{ Acid Orange 8} & 3 & 0.0474 & 0.01612 & 0.0148 & 0.00236 \\
\hline & 5 & 0.0377 & 0.01282 & 0.0151 & 0.00241 \\
\hline & 7 & 0.043 & 0.01462 & 0.0141 & 0.00225 \\
\hline & 9 & 0.0331 & 0.01125 & 0.0129 & 0.00206 \\
\hline & 11 & 0.0213 & 0.00724 & 0.0096 & 0.00153 \\
\hline \multirow{5}{*}{ Acid Blue 29} & 3 & 0.0102 & 0.00347 & 0.0086 & 0.00137 \\
\hline & 5 & 0.009 & 0.00306 & 0.0065 & 0.00104 \\
\hline & 7 & 0.0124 & 0.00422 & 0.0044 & 0.00070 \\
\hline & 9 & 0.0144 & 0.00490 & 0.0044 & 0.00070 \\
\hline & 11 & 0.0097 & 0.00330 & 0.0044 & 0.00070 \\
\hline \multirow{5}{*}{ Acid Blue 113} & 3 & 0.0081 & 0.00275 & 0.2469 & 0.03945 \\
\hline & 5 & 0.0133 & 0.00452 & 0.0324 & 0.00518 \\
\hline & 7 & 0.0175 & 0.00595 & 0.0068 & 0.00109 \\
\hline & 9 & 0.0104 & 0.00354 & 0.0061 & 0.00097 \\
\hline & 11 & 0.0168 & 0.00571 & 0.006 & 0.00096 \\
\hline
\end{tabular}



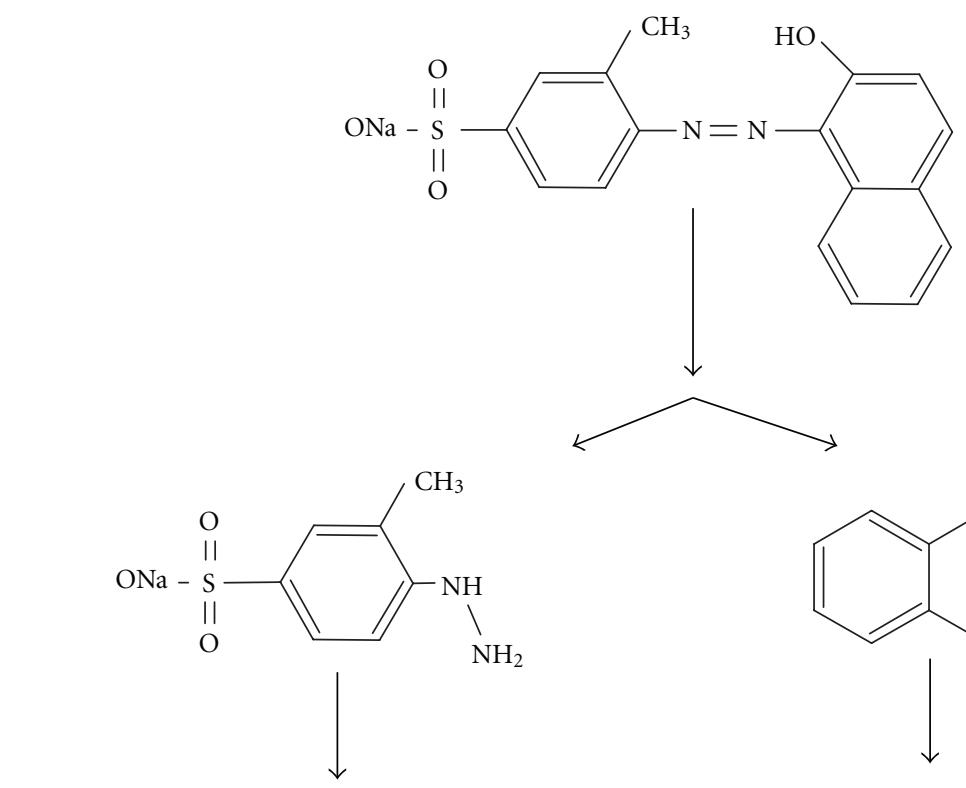<smiles>Oc1ccc2ccccc2c1</smiles><smiles>N[14C](O)Cc1cccc(S(=O)(=O)O)c1</smiles><smiles>Cc1cc2ccccc2c(O)c1O</smiles><smiles>O=Cc1cccc(S(=O)(=O)O)c1</smiles><smiles>O=C1C=Cc2ccccc2C1=O</smiles>

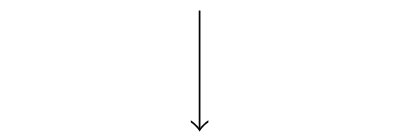

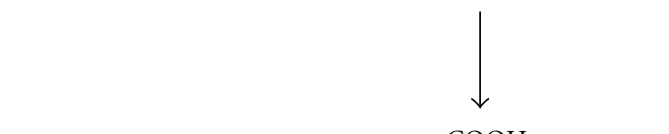

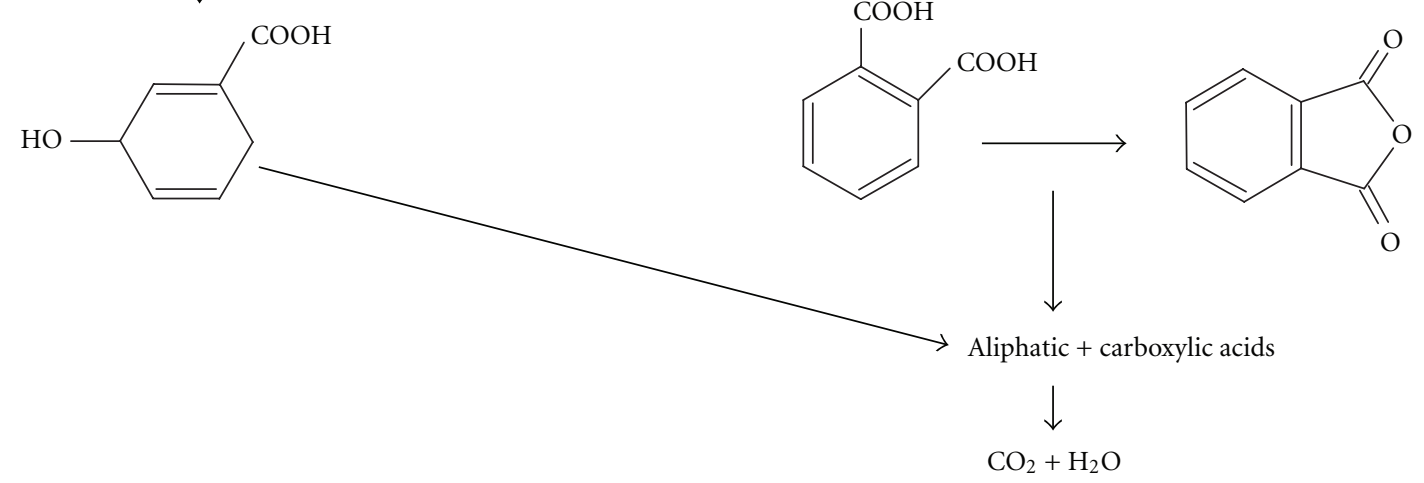

FigURE 5: Reaction pathway of photocatalytic degradation of acid Orange 8.

achieved. By using the pathway modeling of acid Orange 7 in the research of Konstantinou [16], the photodegradation mechanism of acid orange 52 in the research of Galindo et al. [24], and the degradation mechanism of Reactive Orange 4 in the research of Muruganandham et al. [25], the degradation pathway of acid Orange 8 was tried to model based on above models, as shown in Figure 5. However, the model for pathway degradation of acid Blue 29 and acid Blue 113 was not shown in this study because of their complicated mechanism and structure. 


\section{Conclusions}

The development of novel vacuum light sources over the last few years has opened up new possibilities for in situ generation of hydroxyl radicals. Hence, the vacuum-UV photolysis of water is still a field of active research compared to other AOPs. In this study, the results obtained have shown that the VUV photolysis, $\mathrm{VUV} / \mathrm{TiO}_{2}$, and $\mathrm{VUV} / \mathrm{H}_{2} \mathrm{O}_{2}$ processes were capable of efficiently decomposing dye wastewaters. For VUV-based AOPs, the decomposition rates of dyes were significantly raised compared with those by VUV direct photolysis. The individual contribution to the decomposition of dyes by direct photolysis and free hydroxyl radicals destruction generated from the excitement of $\mathrm{O}_{2}$, $\mathrm{H}_{2} \mathrm{O}$, and $\mathrm{H}_{2} \mathrm{O}_{2}$, respectively were differentiated by the proposed conceptual model in the $\mathrm{VUV} / \mathrm{O}_{2}$ and $\mathrm{VUV} / \mathrm{H}_{2} \mathrm{O}_{2}$ systems. The relative contribution to the decomposition of dyes by $\mathrm{OH}^{*}$ indirect oxidation generated from the photolysis of various oxidants $\left(\mathrm{O}_{2}, \mathrm{H}_{2} \mathrm{O}\right.$, and $\left.\mathrm{H}_{2} \mathrm{O}_{2}\right)$ was found to be dependent on the solution $\mathrm{pH}$ values. The decomposing rates of dyes decreased by increasing the molecular size of dyes for all of the VUV-based AOPs.

\section{Acknowledgment}

Financial support from the National Science Council, Taiwan, through Grant NSC97-2221-E-562-001 is gratefully acknowledged.

\section{References}

[1] M. R. Sohrabi and M. Ghavami, "Photocatalytic degradation of direct red 23 dye using $\mathrm{UV} / \mathrm{TiO}_{2}$ : effect of operational parameters," Journal of Hazardous Materials, vol. 153, no. 3, pp. 1235-1239, 2008.

[2] P. Gehringer and H. Eschweiler, "The use of radiation-induced advanced oxidation for water reclamation," Water Science and Technology, vol. 34, no. 7-8, pp. 343-349, 1996.

[3] R. Andreozzi, V. Caprio, A. Insola, and R. Marotta, "Advanced oxidation processes (AOP) for water purification and recovery," Catalysis Today, vol. 53, no. 1, pp. 51-59, 1999.

[4] J. Shang, Y. Du, and Z. Xu, "Kinetics of gas-phase photocatalytic oxidation of heptane over $\mathrm{TiO}_{2}$," Reaction Kinetics and Catalysis Letters, vol. 75, no. 2, pp. 259-265, 2002.

[5] P. Saritha, C. Aparna, V. Himabindu, and Y. Anjaneyulu, "Comparison of various advanced oxidation processes for the degradation of 4-chloro-2 nitrophenol," Journal of Hazardous Materials, vol. 149, no. 3, pp. 609-614, 2007.

[6] Y. Ku, K. Y. Tseng, and C. M. Ma, "Photocatalytic decomposition of gaseous acetone using $\mathrm{TiO}_{2}$ and $\mathrm{Pt} / \mathrm{TiO}_{2}$ catalysts," International Journal of Chemical Kinetics, vol. 40, no. 4, pp. 209-216, 2008.

[7] C. M. Ma, Y. Ku, W. Wang, and F. T. Jeng, "A new optical fiber reactor for the photocatalytic degradation of gaseous organic contaminants," Reaction Kinetics and Catalysis Letters, vol. 94, no. 2, pp. 199-206, 2008.

[8] C. M. Ma, Y. Ku, Y. L. Kuo, Y. C. Chou, and F. T. Jeng, "Effects of silver on the photocatalytic degradation of gaseous isopropanol," Water, Air, \& Soil Pollution, vol. 197, no. 1-4, pp. 313-321, 2009.
[9] G. Heit, A. Neuner, P. Y. Saugy, and A. M. Braun, "Vacuum-UV $(172 \mathrm{~nm})$ actinometry: the quantum yield of the photolysis of water," Journal of Physical Chemistry A, vol. 102, no. 28, pp. 5551-5561, 1998.

[10] W. Han, P. Zhang, W. Zhu, J. Yin, and L. Li, "Photocatalysis of p-chlorobenzoic acid in aqueous solution under irradiation of $254 \mathrm{~nm}$ and $185 \mathrm{~nm}$ UV light," Water Research, vol. 38, no. 19, pp. 4197-4203, 2004.

[11] G. Liu, X. Zhang, J. W. Talley, C. R. Neal, and H. Wang, "Effect of NOM on arsenic adsorption by $\mathrm{TiO}_{2}$ in simulated $\mathrm{As}(\mathrm{III})$ contaminated raw waters," Water Research, vol. 42, no. 8-9, pp. 2309-2319, 2008.

[12] T. Oppenländer and S. Gliese, "Mineralization of organic micropollutants (homologous alcohols and phenols) in water by vacuum-UV-oxidation ( $\mathrm{H} 2 \mathrm{O}-\mathrm{VUV})$ with an incoherent xenon- excimer lamp at $172 \mathrm{~nm}$," Chemosphere, vol. 40, no. 1 , pp. 15-21, 2000.

[13] M. C. Gonzalez and A. M. Braun, "VUV photolysis of aqueous solutions of nitrate and nitrite," Research on Chemical Intermediates, vol. 21, no. 8-9, pp. 837-859, 1995.

[14] G. Heit and A. M. Braun, "VUV-photolysis of aqueous systems: spatial differentiation between volumes of primary and secondary reactions," Water Science and Technology, vol. 35, no. 4, pp. 25-30, 1997.

[15] P. Lenard, "Ueber wirkugen des ultravioletten lichtes auf gasformige korper," Annalen fur Physik, vol. 1, p. 486, 1990.

[16] I. K. Konstantinou and T. A. Albanis, " $\mathrm{TiO}_{2}$-assisted photocatalytic degradation of azo dyes in aqueous solution: kinetic and mechanistic investigations: a review," Applied Catalysis B, vol. 49, no. 1, pp. 1-14, 2004.

[17] A. Fujishima, X. Zhang, and D. A. Tryk, "TiO 2 photocatalysis and related surface phenomena," Surface Science Reports, vol. 63, no. 12, pp. 515-582, 2008.

[18] T. Ochiai, K. Nakata, T. Murakami et al., "Development of solar-driven electrochemical and photocatalytic water treatment system using a boron-doped diamond electrode and $\mathrm{TiO}_{2}$ photocatalyst," Water Research, vol. 44, no. 3, pp. 904910, 2010.

[19] Y. S. Shen and C. C. Lin, "The effect of pH on the decomposition of hydrophenols in aqueous solutions by ultraviolet direct photolysis and the ultraviolet-hydrogen peroxide process," Water Environment Research, vol. 75, no. 1, pp. 54-60, 2003.

[20] F. H. AlHamedi, M. A. Rauf, and S. S. Ashraf, "Degradation studies of Rhodamine $B$ in the presence of $\mathrm{UV} / \mathrm{H}_{2} \mathrm{O}_{2}$," Desalination, vol. 239, no. 1-3, pp. 159-166, 2009.

[21] N. Daneshvar, M. A. Behnajady, M. K. A. Mohammadi, and M. S. S. Dorraji, "UV/ $\mathrm{H}_{2} \mathrm{O}_{2}$ treatment of Rhodamine B in aqueous solution: influence of operational parameters and kinetic modeling," Desalination, vol. 230, no. 1-3, pp. 16-26, 2008.

[22] C. C. Liu, Y. H. Hsieh, P. F. Lai, C. H. Li, and C. L. Kao, "Photodegradation treatment of azo dye wastewater by $\mathrm{UV} / \mathrm{TiO}_{2}$ process," Dyes and Pigments, vol. 68, no. 2-3, pp. 191-195, 2006.

[23] T. Keiichi, P. Kanjana, and H. Teruaki, "Photocatalytic degradation of commercial azo dyes," Water Research, vol. 34, no. 1, pp. 327-333, 2000.

[24] C. Galindo and A. Kalt, " $U V / \mathrm{H}_{2} \mathrm{O}_{2}$ oxidation of azodyes in aqueous media: evidence of a structure-degradability relationship," Dyes and Pigments, vol. 42, no. 3, pp. 199-207, 1999.

[25] M. Muruganandham and M. Swaminathan, "Photocatalytic decolourisation and degradation of Reactive Orange 4 by $\mathrm{TiO}_{2}$-UV process," Dyes and Pigments, vol. 68, no. 2-3, pp. 133-142, 2006. 


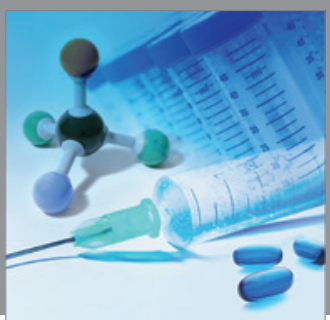

International Journal of

Medicinal Chemistry

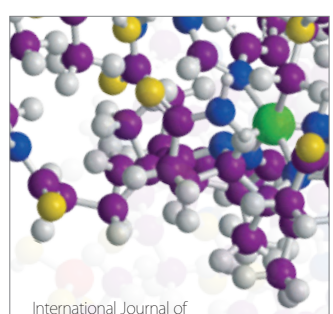

Carbohydrate Chemistry

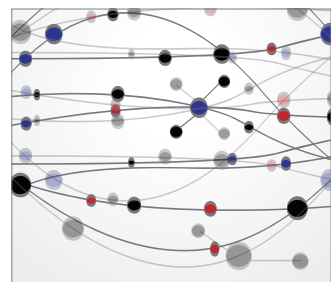

The Scientific World Journal
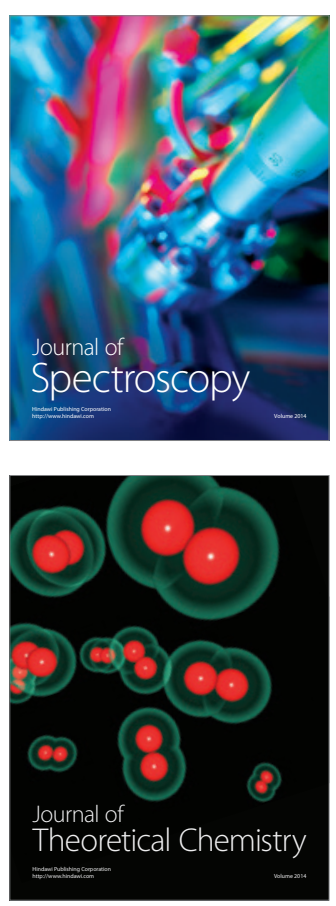
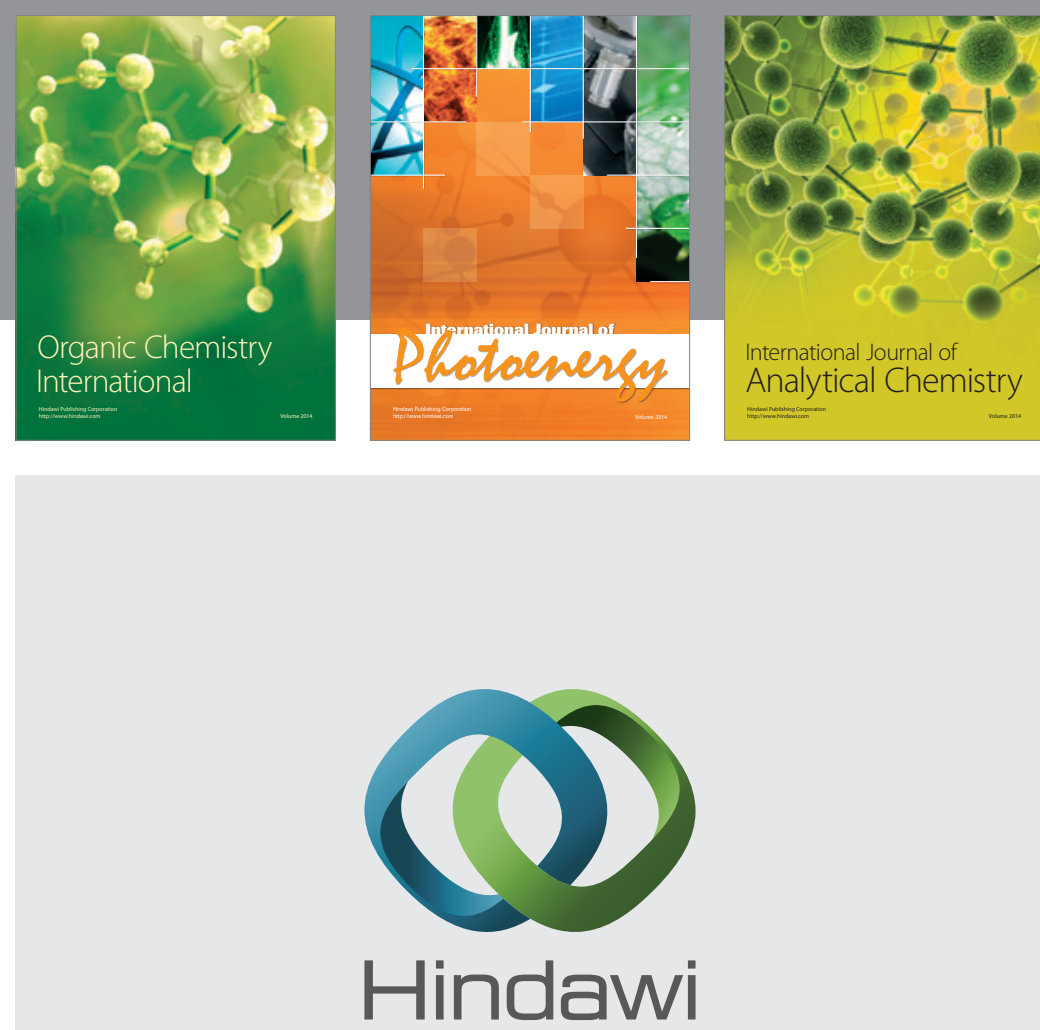

Submit your manuscripts at

http://www.hindawi.com
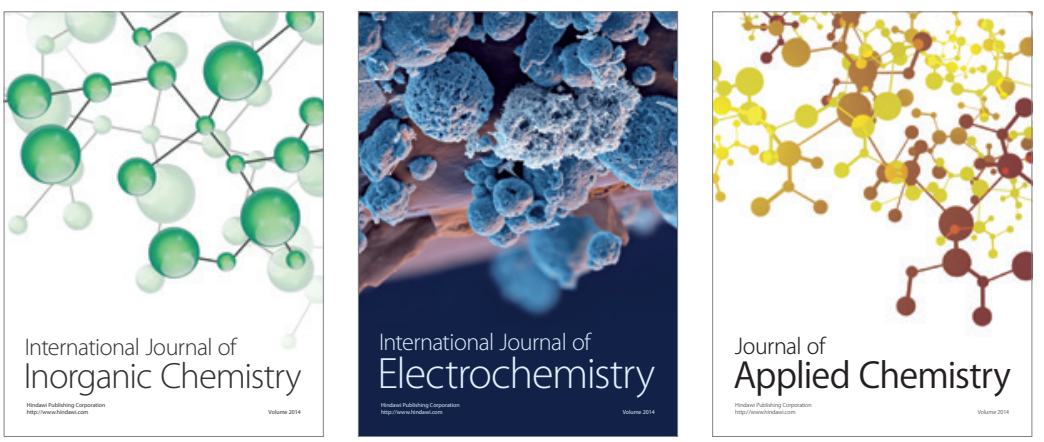

Journal of

Applied Chemistry
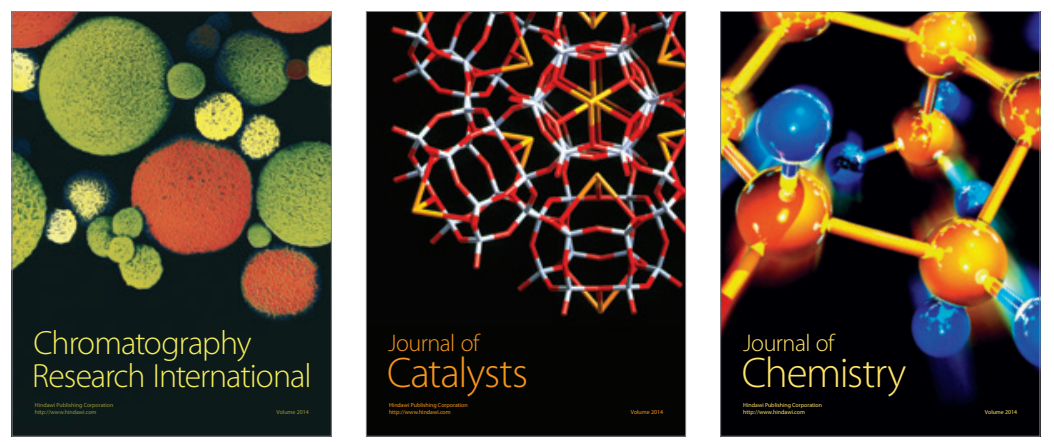
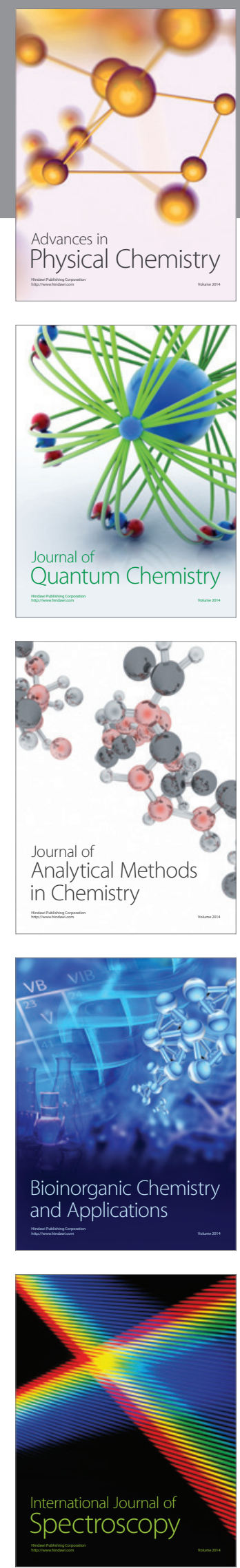